\title{
PENENTUAN KOEFISIEN DISTRIBUSI, EFISIENSI EKSTRAKSI DAN FAKTOR PEMISAHAN PADA EKSTRAKSI GADOLINIUM DAN SAMARIUM DENGAN LIGAN DIBUTILDITIOFOSFAT
}

\author{
Titin Sofyatin*, Nunik Nurlina, Anni Anggraeni, Husein H. Bahti \\ Departemen Kimia, Fakultas Matematika dan Ilmu Pengetahuan Alam, Universitas Padjadjaran \\ Jalan Raya Bandung-Sumedang Km. 21 Jatinangor, Sumedang, Jawa Barat \\ *Alamat Korespondensi: sofyatintitin@yahoo.co.id
}

\begin{abstract}
Abstrak: Unsur tanah jarang merupakan bahan penting dalam berbagai aplikasi teknologi tinggi, Pemisahan dan pemurnian unsur tanah jarang sangat sulit dilakukan karena unsur tanah jarang memiliki kemiripan sifat antara satu dengan yang lainnya. Oleh karena itu, perlu dilakukan pengembangan metode-metode pemisahan dan pemurnian unsur tanah jarang dari mineral-mineralnya, salah satunya dengan metode ekstraksi pelarut dengan penambahan ligan. Tujuan dari penelitian ini adalah menentukan koefisien distribusi (Kd), efisiensi ekstraksi $(\% \mathrm{E})$ dan faktor pemisahan $(\alpha)$ untuk ekstraksi gadolinium dan samarium menggunakan ligan dibutilditiofosfat (DBDTP). Parameter dasar ditentukan melalui percobaan ekstraksi larutan gadolinium dan samarium standar menggunakan ligan DBDTP dengan heksana dan kloroform sebagai pelarut pengekstrak. Ekstraksi dilakukan pada kondisi optimum dan proses ekstraksi dipantau dengan menentukan konsentrasi logam menggunakan ICPOES. Dari data ekstraksi, diperoleh nilai Kd gadolinium dengan pelarut kloroform sebesar 0,89 , $\% \mathrm{EGd}=55,29 \%$, dan $\alpha \mathrm{Gd} / \mathrm{Sm}=1,09$. Nilai Kd samarium dengan pasangan pelarut air-kloroform sebesar 0,82, $\% \mathrm{ESm}=52,43 \%$ dan $\alpha \mathrm{Sm} / \mathrm{Gd}=0,92$. Nilai $\mathrm{Kd}$ gadolinium dengan pasangan pelarut air-heksana sebesar 1,17 , $\% \mathrm{EGd}=64,29 \%$, dan $\alpha \mathrm{Gd} / \mathrm{Sm}=0,87$. Nilai $\mathrm{Kd}$ samarium dengan pasangan pelarut air-heksana sebesar 1,35 , $\% \mathrm{ESm}=68,74 \%$ dan $\alpha \mathrm{Sm} / \mathrm{Gd}=1,15$.
\end{abstract}

Kata kunci: Gadolinium, Samarium, ekstraksi, DBDTP, ICP-OES.

Abstract: Rare earth elements is an important material in many high-tech applications. Separation and purification of rare earths is very difficult because of rare earth elements have similar properties to each other. Therefore, it is necessary to develop methods of separation and purification of rare earths from their minerals, one of them with a solvent extraction method with the addition of ligand. The purpose of this research is to determine distribution coefficient $(K d)$, extraction efficiency $(\% E)$ and separation factor $(\alpha)$ for extraction of gadolinium and samarium use dibutyldithiophosphate ligand (DBDTP). The basic parameters are determined through trial extraction of the gadolinium and samarium standard solution metal using DBDTP ligand with hexane and chloroform as extracting solvent. Extraction is done in optimum conditions and the extraction process is monitored by determining the concentration of metals using ICP-OES. From the data extraction, Kd values of gadolinium with the pair of water-chloroform solvent is $0.89, \% E G d=55.29 \%$, and $\alpha G d / S m=1.09$. $K d$ values of samarium with the pair of water-chloroform solvent is $0.82, \% E S m=52.43 \%$ and $\alpha S m / G d=0.92$. $K d$ values of gadolinium with the pair of water-hexane solvent is $1.17, \% E G d=64.29 \%$, and $\alpha G d / S m=0.87$. $K d$ values of samarium with the pair of water-hexane solvent is $1.35, \% E S m=68.74 \%$ and $\alpha S m / G d=1.15$.

Keywords: rare earth elements, DBDTP, extraction, ICP-OES.

\section{PENDAHULUAN}

Pengembangan metode pemisahan dan analisis unsur tanah jarang (UTJ) telah menarik perhatian banyak peneliti karena unsur-unsur ini merupakan bahan yang menunjang perkembangan ilmu dan teknologi. Penggunaan UTJ ini antara lain untuk superkonduktor, laser, magnet permanen, alat-alat elektronik dan keramik (Christie et al., 1998). Sejauh ini mineral-mineral yang diproduksi oleh perusahaanperusahaan tambang belum diproses untuk menghasilkan fraksi tanah jarangnya, melainkan langsung diekspor dalam bentuk mineralnya. Hal tersebut disebabkan karena kita belum mempunyai teknologi untuk menghasilkan UTJ yang lebih murni. Oleh karena itu, kita perlu berinovasi mengembangkan metode-metode isolasi, pemisahan dan pemurnian untuk memproduksi UTJ dari mineralnya, atau memodifikasi metode-metode yang telah ada untuk memproduksi unsur-unsur tersebut dalam skala yang lebih besar.

UTJ dapat ditemukan dalam beberapa jenis mineral seperti basnasit, monasit, dan senotim (Morais \& Ciminelli, 2007). Pemanfaatan mineral monasit ini sangat tinggi dibanding mineral UTJ lainnya diantara kandungannya yaitu unsur gadolinium (Gd) dan samarium (Sm).

Dikarenakan sifat paramagnetiknya Gd digunakan sebagai bahan contrast agent untuk keperluan pencitraan medis Magnetic Resonance Imaging (MRI) (Gupta \& Krishnamurthy, 2005). Sedangkan salah satu kegunaan Sm yaitu sebagai bahan pembuat magnet dan laser (Christie et al., 1998). Kesulitan untuk memperoleh UTJ murni adalah dalam memisahkan antara UTJ yang satu dengan unsur yang 
lainnya, akibat dari sifatnya yang mirip, sehingga cara kimia seperti kristalisasi, fraksionasi, pertukaran ion dan teknik ekstraksi pelarut sulit dilakukan (Gupta \& Krishnamurthy, 2005). Namun, diantara semua metode pemisahan, ekstraksi pelarut merupakan metode yang paling sukses digunakan. Untuk mengekstraksi UTJ, sejumlah kajian telah dilakukan dengan menggunakan pelarut organik yang mengandung ligan-ligan pembentuk kompleks. Dalam studi mengenai kromatografi logam-logam transisi, Bahti et al. (1990) telah menggunakan ligan dialkilditiofosfat sebagai ligan pengompleks dalam tahap ekstraksi logam tersebut. Unsur-unsur lantanida dapat membentuk senyawa khelat yang baik dengan senyawa asam fosfat, asam fosfit dan tributilfosfat, oleh karena itu senyawa-senyawa ligan tersebut dapat digunakan untuk mengekstraksi unsur-unsur lantanida (Ozturk et al., 2010).

Dalam penelitian ini dipelajari penggunaan ligan dibutilditiofosfat dengan beberapa pelarut organik untuk mengekstraksi Gd dan Sm.

\section{BAHAN DAN METODE Bahan}

Bahan kimia yang digunakan pada penelitian adalah asam asetat, asam borat, asam nitrat, $n$ butanol, difosforpentasulfida, natrium tetraborat, etil asetat, gas nitrogen, heksana, kalium klorida, kloroform, metanol, natrium asetat, natrium hidroksida, gadolinium klorida, dan samarium klorida. Semua bahan kimia tersebut berkualitas pro analysis dan berasal dari Aldrich dan Merck.

\begin{abstract}
Alat
Inductively Coupled Plasma-Optical Emission Spectrometry (ICP-OES) untuk analisis logam dalam fase air hasil ekstraksi (Hou \& Jones, 2000), pHmeter untuk mengatur $\mathrm{pH}$ larutan, serta corong pisah digunakan untuk proses ekstraksi pelarut.
\end{abstract}

\section{Pembuatan Ligan DBDTP}

Sebanyak 2,8 gram difosforpentasulfida dimasukkan ke dalam labu leher tiga yang sudah dipanaskan hingga $80^{\circ} \mathrm{C}$. Ditambahkan $n$-butanol sebanyak $\pm 25 \mathrm{~mL}$ sambil dialiri gas nitrogen, lalu dibiarkan sampai semua difosforpentasulfida bereaksi. Larutan didinginkan pada suhu ruangan dan ditambahkan larutan natrium hidroksida $1 \mathrm{M}$ sampai $\mathrm{pH}$ larutan netral atau sedikit basa. Larutan didiamkan selama 24 jam, kemudian dievaporasi pada suhu $80^{\circ} \mathrm{C}$ sampai terbentuk padatan putih. Padatan putih tersebut disaring dan dicuci dengan sedikit metanol, lalu direkristalisasi dalam metanol dan dikeringkan pada suhu ruang.

\section{Penentuan pH Optimum Ekstraksi}

Sebanyak $20 \mathrm{~mL}$ larutan standar samarium dan gadolinium 100 ppm masing-masing ditempatkan ke dalam gelas kimia dan diatur $\mathrm{pH}$ larutan dengan penambahan larutan asam nitrat $1 \mathrm{M}$ hingga $\mathrm{pH} 2$ dan ditambahkan 2,5 mL larutan buffer sesuai kondisi $\mathrm{pH}$. Larutan dipipet sebanyak $20 \mathrm{~mL}$ dimasukkan ke dalam corong pisah, ditambahkan $20 \mathrm{~mL}$ ligan DBDTP dengan perbandingan mol logam : ligan = 1:3 dan larutan dikocok selama 5 menit. Larutan dalam corong pisah diekstraksi dengan $4 \times 5 \mathrm{~mL}$ heksana selama 15 menit, lalu dibiarkan sampai larutan terpisah. Fase air dan fase organik yang terbentuk dipisahkan. Fase air dianalisis dengan ICPOES. Prosedur yang sama dilakukan untuk variasi $\mathrm{pH}$ ekstraksi 3, 4, 5, 7, dan 9, serta untuk pelarut kloroform.

\section{Ekstraksi Sampel Simulasi}

Sebanyak $20 \mathrm{~mL}$ sampel simulasi diatur $\mathrm{pH}$ nya dengan penambahan larutan natrium hidroksida $1 \mathrm{M}$ hingga mencapai kondisi $\mathrm{pH}$ optimum, kemudian ditambahkan 2,5 mL larutan buffer sesuai kondisi $\mathrm{pH}$ optimum sambil larutan diaduk. Dipipet sebanyak 20 mL dimasukkan ke dalam corong pisah, ditambahkan $20 \mathrm{~mL}$ ligan DBDTP dengan perbandingan mol logam:ligan $=1: 3$ (terhadap mol Sm dan terhadap mol Gd), larutan dikocok selama 5 menit. Larutan dalam corong pisah diekstraksi dengan $4 \times 5 \mathrm{~mL}$ heksana selama 15 menit, lalu dibiarkan sampai larutan terpisah. Fase air dan fase organik yang terbentuk dipisahkan, fase air dianalisis dengan ICPOES. Prosedur yang sama dilakukan untuk pelarut kloroform dan etil asetat.

\section{HASIL DAN PEMBAHASAN Preparasi Ligan DBDTP}

Pada penelitian ini, ligan DBDTP dibuat sesuai dengan prosedur pada penelitian yang dilakukan oleh Bahti et al. (1990) yaitu dengan cara mereaksikan difosforpentasulfida $\left(\mathrm{P}_{2} \mathrm{~S}_{5}\right)$ dengan $n$-butanol pada suhu $800^{\circ} \mathrm{C}$ dengan metode refluks. Selama reaksi berlangsung gas nitrogen dialirkan ke dalam reaktan. Nitrogen digunakan dalam proses ini karena merupakan gas yang inert sehingga tidak akan bereaksi dengan zat yang direaksikan. Penggunaan gas nitrogen bertujuan untuk mencegah terjadinya hidrolisis dari fosfor pentasulfida oleh udara sehingga mengganggu proses sintesis. Apabila terhidrolisis, maka fosfor pentasulfida akan menjadi asam fosfat dan dihidrogen sulfur.

$$
2 \mathrm{P}_{2} \mathrm{~S}_{5}+16 \mathrm{H}_{2} \mathrm{O} \longrightarrow \underset{\text { (Ozturk et al., 2010). }}{4}
$$

Dalam bentuk asamnya ligan DBDTP ini memberikan bau yang sangat menyengat dan mudah teroksidasi oleh udara sedangkan dalam bentuk garamnya akan lebih stabil dan tahan lama.

\section{Ekstraksi Gd(III) dan Sm(III) Individu dengan DBDTP}

Gd(III) dan Sm(III) masing-masing diekstraksi pada kondisi pH 2, 3, 4, 5, 7 dan 9 (mewakili kondisi $\mathrm{pH}$ asam, netral dan basa) menggunakan pelarut 
organik heksana dan kloroform dengan menggunakan ligan DBDTP pada perbandingan mol logam : mol ligan $=1: 3$. Dalam proses ekstraksi, pembentukan kompleks tidak bermuatan adalah tahapan yang sangat penting. Apabila kompleks memiliki muatan, maka senyawa tersebut tidak dapat terdistribusi ke fase organik sehingga tidak dapat terekstrak. Perlakuan ekstraksi dengan variasi $\mathrm{pH}$ dilakukan untuk mengetahui pengaruh $\mathrm{pH}$ terhadap terjadinya pembentukan kompleks karena salah satu faktor yang berpengaruh terhadap pembentukkan kompleks adalah kondisi $\mathrm{pH}$ selain dipengaruhi oleh muatan logam dan ligan.

Berdasarkan hasil percobaan, ekstraksi Gd(III) dan Sm(III) dengan pelarut kloroform dapat dilakukan pada kondisi pH 2 dan 3. Sedangkan pada pH 4 dan 5, setelah ekstraksi terbentuk emulsi yang sulit dihilangkan sehingga kesetimbangan sulit tercapai sedangkan pada $\mathrm{pH} 7$ dan $\mathrm{pH} 9$ (kondisi basa) logam sudah mulai mengendap. Untuk pelarut heksana dalam ekstraksi Gd(III) dan Sm(III) dapat dilakukan pada kondisi pH 2, 3 dan 4, karena pada pH 5 terbentuk emulsi, pada $\mathrm{pH} 7$ dan $\mathrm{pH} 9$ logam sudah mulai mengendap.

\section{Analisis dengan Instrumen ICP-OES}

Analisis dengan instrumen ICP-OES dilakukan terhadap fase air hasil ekstraksi. Sebelum pengukuran dilakukan, terlebih dahulu dibuat larutan standar logam 1-5 ppm yang konsentrasinya telah diketahui.
Larutan standar logam ini digunakan untuk pembuatan kurva baku. Dari kurva baku tersebut, dapat diperoleh persamaan regresi linier yang selanjutnya digunakan untuk menentukan konsentrasi logam dalam fase air yang dianalisis.

\section{Penentuan Konsentrasi Gadolinium dan Samarium Individu Hasil Ekstraksi}

Dari hasil analisis yang dilakukan dapat dihitung konsentrasi ion logam pada fase air dan fase organik. Dari data intensitas, selanjutnya juga dapat ditentukan nilai rasio distribusi dan efisiensi ekstraksi untuk masing-masing ion logam hasil ekstraksi, hasilnya dapat dilihat pada Tabel 1 dan Tabel 2 .

Berdasarkan data pada Tabel 1 dan Tabel 2 dapat ditentukan bahwa kondisi optimum untuk pemisahan Gd(III) dan Sm(III) adalah pada $\mathrm{pH} 2$ untuk pelarut kloroform dan pada pH 3 untuk pelarut heksana. Kondisi tersebut dipilih karena menghasilkan perbedaan nilai efisiensi ekstraksi untuk Gd(III) dan Sm(III) yang cukup jauh. Pada kondisi tersebut jumlah Sm(III) yang terdistribusi ke fase organik cukup banyak, dan sebaliknya Gd(III) memiliki nilai efisiensi ekstraksi yang rendah. Hal tersebut menunjukkan bahwa $\mathrm{pH}$ larutan berpengaruh terhadap konstanta kestabilan kompleks yang terbentuk, sehingga menyebabkan perbedaan terhadap nilai efisiensi yang diperoleh.

Tabel 1. Data efisiensi ekstraksi (\%E) hasil ekstraksi Gd(III) pada variasi $\mathrm{pH}$ dan pelarut organik (perbandingan mol logam: mol ligan= 1:3).

\begin{tabular}{clcccc}
\hline $\mathbf{p H}$ & \multirow{2}{*}{ Pelarut } & $\begin{array}{c}{[\mathbf{G d}]_{\mathrm{awal}}} \\
(\mathbf{m g} / \mathbf{L})\end{array}$ & $\begin{array}{c}{[\mathbf{G d}]_{\mathrm{aq}}} \\
(\mathbf{m g} / \mathbf{L})\end{array}$ & $\begin{array}{c}{[\mathbf{G d}]_{\mathrm{org}}} \\
(\mathbf{m g} / \mathbf{L})\end{array}$ & $\mathbf{\% E}$ \\
\hline $\mathbf{2 , 0 3}$ & kloroform & 85,67 & 41,92 & 43,75 & 51,06 \\
$\mathbf{3 , 0 1}$ & kloroform & 87,55 & 38,62 & 48,93 & 55,89 \\
$\mathbf{2 , 0 3}$ & heksana & 73,77 & 34,58 & 39,19 & 53,13 \\
$\mathbf{3 , 0 1}$ & heksana & 78,11 & 39,56 & 38,55 & 49,35 \\
$\mathbf{4 , 0 2}$ & heksana & 76,61 & 9,14 & 67,47 & 88,02 \\
\hline
\end{tabular}

Tabel 2. Data efisiensi ekstraksi (\%E) hasil ekstraksi Sm(III) pada variasi pH dan pelarut organik (perbandingan mol logam: mol ligan=1:3).

\begin{tabular}{clcccc}
\hline $\mathbf{p H}$ & Pelarut & $\begin{array}{c}{[\mathbf{S m}]_{\mathrm{awal}}} \\
(\mathbf{m g} / \mathbf{L})\end{array}$ & $\begin{array}{c}{[\mathbf{S m}]_{\mathrm{aq}}} \\
(\mathbf{m g} / \mathbf{L})\end{array}$ & $\begin{array}{c}{[\mathbf{S m}]_{\text {org }}} \\
(\mathbf{m g} / \mathbf{L})\end{array}$ & $\mathbf{\% E}$ \\
\hline $\mathbf{2 , 0 3}$ & kloroform & 83,05 & 22,75 & 60,31 & 72,61 \\
$\mathbf{3 , 0 1}$ & kloroform & 70,97 & 33,58 & 37,40 & 52,69 \\
$\mathbf{2 , 0 3}$ & heksana & 70,97 & 33,05 & 37,93 & 53,44 \\
$\mathbf{3 , 0 1}$ & heksana & 83,05 & 4,61 & 78,44 & 94,45 \\
$\mathbf{4 , 0 2}$ & heksana & 83,95 & 25,84 & 58,10 & 69,21 \\
\hline
\end{tabular}


Tabel 3. Data efisiensi ekstraksi (\%E) Gd(III) dan Sm(III) hasil ekstraksi sampel simulasi pada (a) pH 2 dengan pasangan pelarut air-kloroform; (b) pada $\mathrm{pH} 3$ dengan pasangan pelarut air-heksana.

\begin{tabular}{|c|c|c|c|c|c|c|c|c|}
\hline \multirow[b]{2}{*}{ Sampel } & \multicolumn{3}{|c|}{ Gd (III) } & \multirow[b]{2}{*}{$\% \mathbf{E}_{\mathbf{G d}}$} & \multicolumn{3}{|c|}{ Sm (III) } & \multirow[b]{2}{*}{$\% \mathbf{E}_{\mathrm{Sm}}$} \\
\hline & $\begin{array}{c}{[\mathbf{G d}]_{\text {awal }}} \\
(\mathrm{mg} / \mathrm{L})\end{array}$ & $\begin{array}{l}{[\mathbf{G d}]_{\mathrm{aq}}} \\
(\mathrm{mg} / \mathrm{L})\end{array}$ & $\begin{array}{l}{[\mathbf{G d}]_{\text {org }}} \\
(\mathrm{mg} / \mathrm{L})\end{array}$ & & $\begin{array}{c}{[\mathrm{Sm}]_{\text {awal }}} \\
(\mathrm{mg} / \mathrm{L})\end{array}$ & $\begin{array}{l}{[\mathrm{Sm}]_{\mathrm{aq}}} \\
(\mathrm{mg} / \mathrm{L})\end{array}$ & $\begin{array}{c}{[\mathrm{Sm}]_{\text {org }}} \\
(\mathrm{mg} / \mathrm{L})\end{array}$ & \\
\hline 1 & 25,55 & 11,42 & 14,13 & 55,29 & 75,77 & 36,05 & 39,73 & 52,43 \\
\hline 2 & 25,55 & 11,06 & 14,49 & 56,70 & 75,77 & 35,52 & 40,25 & 53,12 \\
\hline
\end{tabular}

(a)

\begin{tabular}{|c|c|c|c|c|c|c|c|c|}
\hline \multirow[b]{2}{*}{ Sampel } & \multicolumn{3}{|c|}{ Gd (III) } & \multirow[b]{2}{*}{$\% \mathbf{E}_{\mathbf{G d}}$} & \multicolumn{3}{|c|}{ Sm (III) } & \multirow[b]{2}{*}{$\% \mathbf{E}_{\mathrm{Sm}}$} \\
\hline & $\begin{array}{c}{[\mathbf{G d}]_{\text {awal }}} \\
(\mathbf{m g} / \mathbf{L})\end{array}$ & $\begin{array}{l}{[\mathbf{G d}]_{\mathrm{aq}}} \\
(\mathrm{mg} / \mathbf{L})\end{array}$ & $\begin{array}{l}{[\mathbf{G d}]_{\text {org }}} \\
(\mathrm{mg} / \mathrm{L})\end{array}$ & & $\begin{array}{c}{[\mathrm{Sm}]_{\text {awal }}} \\
(\mathrm{mg} / \mathrm{L})\end{array}$ & $\begin{array}{l}{[\mathrm{Sm}]_{\mathrm{aq}}} \\
(\mathrm{mg} / \mathrm{L})\end{array}$ & $\begin{array}{c}{[\mathrm{Sm}]_{\text {org }}} \\
(\mathrm{mg} / \mathrm{L})\end{array}$ & \\
\hline 1 & 25,00 & 8.93 & 16,07 & 64,29 & 74,16 & 23,18 & 50,98 & 68,74 \\
\hline 2 & 25,00 & 12,35 & 12,65 & 50,59 & 74,16 & 38,98 & 35,18 & 47,43 \\
\hline
\end{tabular}

(b)

Keterangan:

sampel $1=$ campuran larutan ion logam Gd:Sm=1:3; DBDTP $=450 \mathrm{ppm}$

sampel $2=$ campuran larutan ion logam $\mathrm{Gd}: \mathrm{Sm}=1: 3 ; \mathrm{DBDTP}=150 \mathrm{ppm}$

\section{Penentuan Konsentrasi Gadolinium Samarium Hasil Ekstraksi Sampel Simulasi}

dan

Sisa ion logam Gd dan Sm yang tertinggal di fase air diukur konsentrasinya dengan instrumen ICPOES, yang selanjutnya dilakukan perhitungan nilai efisiensi ekstraksi untuk masing-masing logam. Hasilnya dapat dilihat pada Tabel 3 dan Tabel 4.

Untuk ekstraksi Gd(III) dan Sm(III) pada sistem campuran hasilnya berbeda dengan ion logam tunggal. Pada sistem campuran, efisiensi ekstraksi Gd(III) pada pH 2 (dengan pelarut kloroform) dan konsentrasi ligan DBDTP $150 \mathrm{ppm}$ (mol Gd: mol ligan $=1: 3$ ) adalah $56,70 \%$ sedangkan pada $\mathrm{pH} 3$ (dengan pelarut heksana) adalah 50,59\%. Saat digunakan konsentrasi ligan DBDTP 450 ppm (mol Sm: mol ligan= 1:3) efisiensi ekstraksi Gd(III) pada pH 2 adalah 55,29\% dan pada pH 3 adalah 64,29\%. Sedangkan pada sistem tunggal efisiensi ekstraksi Gd(III) pada pH 2 (dengan pelarut kloroform) adalah $51,06 \%$ dan pada $\mathrm{pH} 3$ (dengan pelarut heksana) adalah 49,35\%. Untuk Sm(III), efisiensi ekstraksi $\mathrm{Sm}(\mathrm{III})$ pada $\mathrm{pH} 2$ dengan konsentrasi ligan DBDTP 450 ppm (mol Sm: mol ligan=1: 3 ) adalah 52,43\% dan pada $\mathrm{pH} 3$ adalah $68,74 \%$. Saat digunakan konsentrasi ligan DBDTP 150 ppm (mol Gd: mol ligan $=1: 3$ ) efisiensi ekstraksi Sm(III) pada $\mathrm{pH} 2$ adalah $53,12 \%$ dan pada $\mathrm{pH} 3$ adalah 47,43\%. Sedangkan pada sistem tunggal efisiensi ekstraksi Sm(III) pada pH 2 (dengan pelarut kloroform) adalah $72,61 \%$ dan pada $\mathrm{pH} 3$ (dengan pelarut heksana) adalah $94,45 \%$. Hasil tersebut dikarenakan sifat fisik dan sifat kimia dari Gd(III) dan Sm(III) tidak jauh berbeda sehingga kompleks yang terbentuk antara Gd-DBDTP dan Sm-DBDTP saling mempengaruhi, dan menyebabkan nilai efisiensi ekstraksi kedua ion logam tersebut menjadi tidak terlalu jauh, sehingga keduanya sulit dipisahkan.

Penentuan Nilai Koefisien Distribusi (Kd) dan Faktor Pemisahan (a) Gadolinium dan Samarium pada Sampel Simulasi

Berdasarkan data yang diperoleh dari analisis dengan instrumen ICP-OES dan pengolahan data, selanjutnya dihitung nilai $\mathrm{Kd}$ dan $\alpha$ untuk Gd(III) dan Sm(III). Hasilnya dapat dilihat pada Tabel 4 dan Tabel 5.

Berdasarkan data pada Tabel 4, nilai faktor pemisahan untuk Gd dan $\mathrm{Sm}(\alpha \mathrm{Gd} / \mathrm{Sm})$ pada $\mathrm{pH} 2$ dengan pelarut kloroform lebih mendekati satu dibandingkan dengan pelarut heksana pada $\mathrm{pH} \mathrm{2,}$ yang berarti bahwa heksana lebih baik digunakan sebagai pelarut organik pada ekstraksi Gd(III) dan Sm(III) dibandingkan dengan kloroform. Dilihat dari nilai faktor pemisahan $\mathrm{Gd} / \mathrm{Sm}$ yang diperoleh menunjukkan bahwa dalam sistem campuran, Gd dan Sm masih sulit untuk dipisahkan dengan ekstraksi pelarut menggunakan ligan DBDTP. Karena syarat untuk suatu logam dapat dipisahkan dari campurannya menggunakan metode ekstraksi pelarut yaitu jika nilai faktor pemisahann $\alpha$ kurang dari atau lebih dari satu $(\alpha>1<\alpha)$. Sama halnya jika digunakan konsentrasi ligan DBDTP 150 ppm saat ekstraksi (data pada Tabel 5), nilai faktor pemisahannya pun tidak jauh berbeda dengan saat digunakan ligan DBDTP 450 ppm. Begitu pula dengan kecilnya nilai 
Tabel 4. Nilai koefisien distribusi (Kd) dan faktor pemisahan $(\alpha)$ hasil ekstraksi Gd(III) dan Sm(III) pada sampel simulasi ( $\mathrm{mol} \mathrm{Sm}:$ mol DBDTP= 1:3).

\begin{tabular}{lclccc}
\hline Logam & $\mathbf{p H}$ & Pelarut & $\mathbf{K d}$ & $\boldsymbol{\alpha}_{\mathbf{G d} / \mathbf{S m}}$ & $\boldsymbol{\alpha}_{\mathbf{S m} / \mathbf{G d}}$ \\
\hline \multirow{2}{*}{ Gd } & 3 & heksana & 1,17 & 0,87 & - \\
& 2 & kloroform & 0,89 & 1,09 & - \\
\hline \multirow{2}{*}{ Sm } & 3 & heksana & 1,35 & - & 1,15 \\
& 2 & kloroform & 0,82 & - & 0,92 \\
\hline
\end{tabular}

Keterangan: konsentrasi DBDTP yang digunakan $=450 \mathrm{ppm}$

Tabel 5. Nilai koefisien distribusi (Kd) dan faktor pemisahan ( $\alpha$ ) hasil ekstraksi Gd(III) dan Sm(III) pada sampel simulasi (mol Gd : mol DBDTP= 1:3).

\begin{tabular}{lclccc}
\hline Logam & $\mathbf{p H}$ & Pelarut & Kd & $\boldsymbol{\alpha}_{\mathbf{G d} / \mathbf{S m}}$ & $\boldsymbol{\alpha}_{\mathbf{S m} / \mathbf{G d}}$ \\
\hline \multirow{2}{*}{ Gd } & 3 & heksana & 0,77 & 1,11 & - \\
& 2 & kloroform & 0,93 & 1,12 & - \\
\hline \multirow{2}{*}{ Sm } & 3 & heksana & 0,70 & - & 0,90 \\
& 2 & kloroform & 0,83 & - & 0,90 \\
\hline
\end{tabular}

Keterangan: konsentrasi DBDTP yang digunakan $=150 \mathrm{ppm}$

koefisien distribusi yang diperoleh, yang menunjukkan bahwa jumlah logam yang terdistribusi ke fase organik sangat sedikit. Sehingga dari datadata yang diperoleh menunjukkan bahwa Gd(III) dan $\mathrm{Sm}(\mathrm{III})$ pada sistem campuran masih belum terpisah.

\section{KESIMPULAN}

Berdasarkan hasil penelitian yang dilakukan, dapat ditentukan nilai koefisien distribusi, faktor pemisahan dan efisiensi ekstraksi dalam ekstraksi gadolinium dan samarium dengan ligan DBDTP sebagai berikut:

- Dengan pelarut pengekstraksi kloroform nilai $\mathrm{Kd}_{\mathrm{Gd}}=0,89, \% \mathrm{E}_{\mathrm{Gd}}=55,29 \%$, dan $\alpha_{\mathrm{Gd} / \mathrm{Sm}}=1,09$. Untuk nilai $\quad \mathrm{Kd}_{\mathrm{Sm}}=0,82, \quad \% \mathrm{E}_{\mathrm{Sm}}=52,43 \%$ dan $\alpha_{\mathrm{Sm} / \mathrm{Gd}}=0,92$.

- Dengan pelarut heksana menghasilkan nilai $\mathrm{Kd}_{\mathrm{Gd}}=1,17, \quad \% \mathrm{E}_{\mathrm{Gd}}=64,29 \%$, dan $\quad \alpha_{\mathrm{Gd} / \mathrm{Sm}}=0,87$. Untuk nilai $\mathrm{Kd}_{\mathrm{Sm}}=1,35, \quad \% \mathrm{E}_{\mathrm{Sm}}=68,74 \%$ dan $\alpha_{\mathrm{Sm} / \mathrm{Gd}}=1,15$.

Pelarut heksana lebih baik digunakan untuk ekstraksi gadolinium dan samarium dibandingkan pelarut kloroform. Kemampuan pemisahan DBDTP sebagai pengompleks dalam ekstraksi gadolinium dan samarium dengan teknik ekstraksi pelarut masih rendah.

\section{DAFTAR PUSTAKA}

Bahti, H.H., Mulyasih, Y. \& Anggraeni, A. (2011). Extraction and chromatographic studies on rare earth elements (REEs) from their minerals, Proceedings of the $2^{\text {nd }}$ International Seminar on Chemistry. 421-430.

Christie, T., Braithwaite, B. \& Tulloch, A. (1998). Rare Earth and Related Elements. Mineral Commodity Report, 17.

Gupta, C.K. \& Krishnamurthy, N. (2005). Extractive metallurgyof rare-earths, CRC Press.London.

Hou, X. \& Jones, B.T. (2000). Inductively Coupled Plasma/Optical Emission Spectrometry. Encyclopedia of Analytical Chemistry, pp.94689485.

Morais, C.A. \& Ciminelli, V.S.T. (2007). Selection of solvent extraction reagent for the separation of europium(III) and gadolinium(III), Minerals Engineering, 20: 747-752.

Ozturk, T., Ertas, E., \& Mert, O. 2010. A Berzelius Reagent, Phosphorus Decasulfide (P4S10), in Organic Syntheses, Chemical Reviews, 110(6): 3419-3478. 